\title{
SIMULATION-DRIVEN OPTIMIZATION OF URBAN BUS TRANSPORT
}

\author{
RITESH KUMAR KALLE, PRASHANT KUMAR, SAIMA MOHAN \& MASAYUKI SAKATA \\ Hitachi India Pvt. Ltd., Bangalore, India
}

\begin{abstract}
Urban bus transport is an important mode of public transportation in developing countries and accounts for the major share of daily commuter demand in growing cities. However, many of these systems are not optimized and suffer from delays, cancellations and over-crowding, leading to losses. In recent times, intelligent transport systems (ITS) have been deployed to improve the bus operations. However, the ITS deployed in developing nations have been limited to monitoring daily operations, largely due to their dynamic and unpredictive demand pattern. Bus transport operators need new ITS solutions for schedule optimization and fleet management to improve the efficiency and profitability. Simulation driven optimization of operational parameters is one of the methods to propose the advantages of integrating ITS solutions with the bus operations. The primary data utilized for analysis includes both the static and dynamic sources. The static data consists of route, schedule, vehicle and historical ticket information. Whereas the dynamic data includes GPS traces and Automatic Vehicle Location System (AVLS) information. The simulation consists of models of bus operations as well as the passenger ridership. Each of these are inter-dependent and directly impact the measurable performance indicators for the transport operators (for example, passenger load factor, departure headways, vehicle utilization and earnings). Therefore, the goal of the proposed simulator is to optimize these measurable key performance indicators (KPI) through their iterative schedule evaluation. In this paper, the methods used to model bus transportation are investigated and the impact on measurable performance indicators are evaluated. The simulator can not only be used to optimize the schedule, but also to evaluate passenger load and bus fleet utilization scenarios. In addition to evaluation of schedule for typical urban scenario, the conditions in developing countries and application difficulties are discussed. In summary, the results indicate that demand driven scheduling results in cost savings and efficiency improvement. Keywords: discrete event simulation, bus transport, schedule optimization.
\end{abstract}

\section{INTRODUCTION}

Public transportation infrastructure in developing countries is a crucial requirement towards sustaining rapid growth and workforce migration to urban areas due to industrialization. Meanwhile smaller developing cities have fewer resources to implement modern and efficient modes of public transport. Pojani and Stead [1] report that they also suffer from lower modal shares of public transport, urban congestion and low levels of service as compared to cities in the developed world. In recent times, intelligent transport systems (ITS) based solutions have been introduced as technological interventions to improve the levels of service through integration of public information systems (PIS), automatic vehicle location systems (AVLS), electronic ticketing systems (ETM) and scheduling tools, etc. While they serve as means to monitor and control bus operations, the data accumulated over period have not been effectively utilized for optimization. One of the challenges for the effective use of this data has been the non-availability of tools and methodologies to transform it to measurable performance indicators. Simulation driven optimization is a novel approach to utilize accumulated operational ITS data and is the primary subject of this paper. 


\subsection{Literature survey}

In research literature, there have been several efforts to simulate and optimize the public bus transportation routes using ITS data. In De La Mota and Huerta-Barrientos [2], the authors employ complex networks concept to simulate and evaluate Mexico City's public transport networks including bus services. The results indicate that public transportation network in Mexico City have features of complex networks whose structure is irregular, distributed and dynamically evolving in time. The objective was to understand the accessibility, resilience to removal of transport nodes using Gephi software tool described in Bastian et al. [3]. While this approach is useful for network wide optimization of transport routes, it does not address the specific problem of bus transport schedule simulation and optimization.

Hawas [4] reports a micro-simulation approach to estimate bus route and network travel times. This model not only simulates the vehicular flow, but also the bus operations including different dispatch frequencies and passenger boarding-alighting patterns. Regression models were used to predict both route and overall network travel times. However, does not apply to evaluating the response of passenger boarding-alighting patterns with load factor. Further, Ibarra-Rojas et al. [5] also discussed the research in use of simulation for planning, control.

Song et al. [6] propose a simulation-based approach for sustainable transportation systems evaluation and optimization. The paper proposes optimal combination of transportation planning and operation strategies (e.g. congestion pricing) that minimize generalized costs of multimodal traveling. However, this work makes use of a separate traffic simulation tool VISUM before passing the results to the optimization module. The iterative micro-simulation for all possible permutations of operational strategy, policy till convergence conditions are achieved is unsuitable for city wide transport optimization due to exponential increase in computational requirement. Agent-based simulation model is an alternate approach to analyse the system behaviour based on each passenger's travel choice as an autonomous and independent entity. In Hajinasab et al. [7], authors propose a multi agent simulation model for decision making in urban transport planning. This model accounts for the influence of cost, time, convenience and social norm. However, it does not validate the simulated travels with actual operational data. Table 1 summarizes the related work, gap, novelty of this work.

Iliopoulou and Kepaptsoglou [8] have presented a detailed literature review of usage of ITS data from public transportation for planning and decision making. Especially from the tactical planning perspective, the availability of AVLS and ETM data helps improve the OD demand estimation and thereby timetable design. In Gkiotsalitis and Cats [9], dispatch headways are computed through solution of a quadratic optimization problem considering the demand, headway and travel time variations for different times of the day, operational costs, vehicle capacity and fleet constraints. Further Wang et al. [10] consider the waiting time minimization problem for large scale data set of passenger boarding times in order to generate optimal dispatch schedules. In Yan et al. [11] a reliable schedule design problem is considered accounting for the travel time variance and driver behaviour. A robust optimization model is solved to minimize the schedule deviation and variance. Table 2 summarizes the comparison of state-of-art surveyed and the contribution of the current work.

In this paper, the use of data gathered from ITS services deployed in the network to generate optimized schedule along with the measurable KPIs directly relevant to transport administrators is proposed. Hence, the results can be validated, and future scenario evaluated reliably by the transport operators. In future, this system can be extended to include extraneous events and their impact on transport services, for example: breakdown of bus. This paper is structured as follows: In Section 2, the background of the issues under 
Table 1: Literature survey of simulation methods to optimize bus transport.

\begin{tabular}{|l|l|l|l|}
\hline Approach & Major outcome & Gap in the state of art & $\begin{array}{l}\text { Key novelty in our } \\
\text { proposal }\end{array}$ \\
\hline $\begin{array}{l}\text { Complex network } \\
\text { simulation of } \\
\text { transport plan De } \\
\text { La Mota et al. [2] }\end{array}$ & $\begin{array}{l}\text { Analysis of patterns } \\
\text { of structural } \\
\text { vulnerability, } \\
\text { service accessibility } \\
\text { passenger mobility. }\end{array}$ & $\begin{array}{l}\text { Model does not } \\
\text { consider the } \\
\text { congestion, ridership } \\
\text { data. Hence limited to } \\
\text { network analysis. }\end{array}$ & $\begin{array}{l}\text { Detailed model of each } \\
\text { route with operator data of } \\
\text { trip time, ridership for } \\
\text { schedule optimization is } \\
\text { applied. }\end{array}$ \\
\hline $\begin{array}{l}\text { Micro-simulation } \\
\text { to estimate route, } \\
\text { trip-time Hawas } \\
\text { [4] }\end{array}$ & $\begin{array}{l}\text { Simulated } \\
\text { hypothetical route } \\
\text { network with } \\
\text { different trip } \\
\text { patterns. }\end{array}$ & $\begin{array}{l}\text { Effect of route design } \\
\text { and bus frequencies on } \\
\text { bus ridership is not } \\
\text { captured in this model. }\end{array}$ & $\begin{array}{l}\text { Route model developed } \\
\text { from mobility, ridership } \\
\text { data from ITS; so closely } \\
\text { simulates real scenario. }\end{array}$ \\
\hline $\begin{array}{l}\text { Evaluation } \\
\text { framework for } \\
\text { transport strategy } \\
\text { Song et al. [6] }\end{array}$ & $\begin{array}{l}\text { Simulation and } \\
\text { optimization of } \\
\text { multi-modal } \\
\text { transport strategy. }\end{array}$ & $\begin{array}{l}\text { Authors mention the } \\
\text { computation } \\
\text { complexity of this } \\
\text { method is too high. }\end{array}$ & $\begin{array}{l}\text { Bus schedule is optimized } \\
\text { from operator KPI view on } \\
\text { a route-wise basis to reduce } \\
\text { computational load. }\end{array}$ \\
\hline $\begin{array}{l}\text { Multi-agent } \\
\text { traveller model } \\
\begin{array}{l}\text { Hajinasab et al. } \\
\text { [7] }\end{array}\end{array}$ & $\begin{array}{l}\text { Decision making for } \\
\text { traveller agent using } \\
\text { utility functions of } \\
\text { generalized cost }\end{array}$ & $\begin{array}{l}\text { Considers the trip } \\
\text { assignment only, but } \\
\text { neglects the schedule, } \\
\text { operational issue. }\end{array}$ & $\begin{array}{l}\text { Considers ticket data-based } \\
\text { passenger boarding - } \\
\text { alighting model to optimize } \\
\text { and simulate schedules. }\end{array}$ \\
\hline
\end{tabular}

Table 2: Literature survey of ITS data-based bus transport schedule optimization methods.

\begin{tabular}{|c|c|c|c|}
\hline Approach & Major outcome & Gap in the state of art & $\begin{array}{l}\text { Key novelty in our } \\
\text { proposal }\end{array}$ \\
\hline $\begin{array}{l}\text { Sequential } \\
\text { Quadratic } \\
\text { Programming } \\
\text { Gkiotsalitis and } \\
\text { Cats [9] }\end{array}$ & $\begin{array}{l}\text { Optimal dispatch } \\
\text { headway for high } \\
\text { frequency service } \\
\text { using GTFS, } \\
\text { AVLS, APC data }\end{array}$ & $\begin{array}{l}\text { Does not consider } \\
\text { variations in fleet } \\
\text { size, or day-to-day } \\
\text { variations of ridership } \\
\text { needing short turn } \\
\text { trips, interlining of } \\
\text { services. }\end{array}$ & $\begin{array}{l}\text { Iterative simulation to } \\
\text { determine the heuristic } \\
\text { optimized schedule. } \\
\text { Not limited to high } \\
\text { frequency service, } \\
\text { supports short trips. }\end{array}$ \\
\hline $\begin{array}{l}\text { Big data } \\
\text { analysis of } \\
\text { passenger } \\
\text { smart-card } \\
\text { records } \\
\text { Wang et al. [10] } \\
\end{array}$ & $\begin{array}{l}\text { Granular spatio-- } \\
\text { temporal traffic, } \\
\text { demand } \\
\text { optimized } \\
\text { schedule }\end{array}$ & $\begin{array}{l}\text { Needs high resolution } \\
\text { passenger entry-exit } \\
\text { data as pre-requisite. } \\
\text { Models waiting time } \\
\text { of passengers. }\end{array}$ & $\begin{array}{l}\text { Considers granular } \\
\text { demand model from } \\
\text { ETM transaction data. } \\
\text { Waiting time info. at } \\
\text { stops is not essential } \\
\text { for this model. }\end{array}$ \\
\hline $\begin{array}{l}\text { Monte Carlo } \\
\text { simulation to } \\
\text { solve robust } \\
\text { optimization } \\
\text { Yan et al. [11] }\end{array}$ & $\begin{array}{l}\text { Optimized } \\
\text { schedule with trip } \\
\text { time variance, } \\
\text { driver behaviour }\end{array}$ & $\begin{array}{l}\text { Considers driver } \\
\text { behaviour control on } \\
\text { driving speed to } \\
\text { adjust trips times. } \\
\text { This method would } \\
\text { have safety concerns. }\end{array}$ & $\begin{array}{l}\text { Considers bus arrival } \\
\text { time variance at each } \\
\text { intermediate stop along } \\
\text { with end-to-end trip } \\
\text { time data. More } \\
\text { granular than previous } \\
\text { work. }\end{array}$ \\
\hline
\end{tabular}


consideration is presented. In Section 3, the proposed approach as well as measurable KPIs are discussed. The data models and simulation challenges are discussed in Section 4. The evaluation results for an example scenario are presented in Section 5. Finally, conclusion and future research perspectives are outlined in Section 6.

\section{BACKGROUND}

In this section, typical issues faced by urban bus transport operators in developing countries, especially regarding the planning and scheduling of vehicles are described.

\subsection{Challenges for schedule optimization in developing cities}

\subsubsection{Lack of standardization across data sources and formats}

Public transport operators in developing cities are implementing ITS solutions at various technological stages. However, there is no common data specification for monitoring, control of these operations. Therefore, analytics driven optimization solution deployed on existing information infrastructure need to support a wide variety of formats and compensate for information loss during processing data. This leads to a major bottle neck towards scaling and global optimization of the route network. In our proposed approach as well, the mapping of operator data to simulator's custom format (see Fig. 1) is a challenge and needs to be addressed on a case-by-case basis. This issue is surveyed in detail under the data quality considerations topic of Iliopoulou and Kepaptsoglou [8].

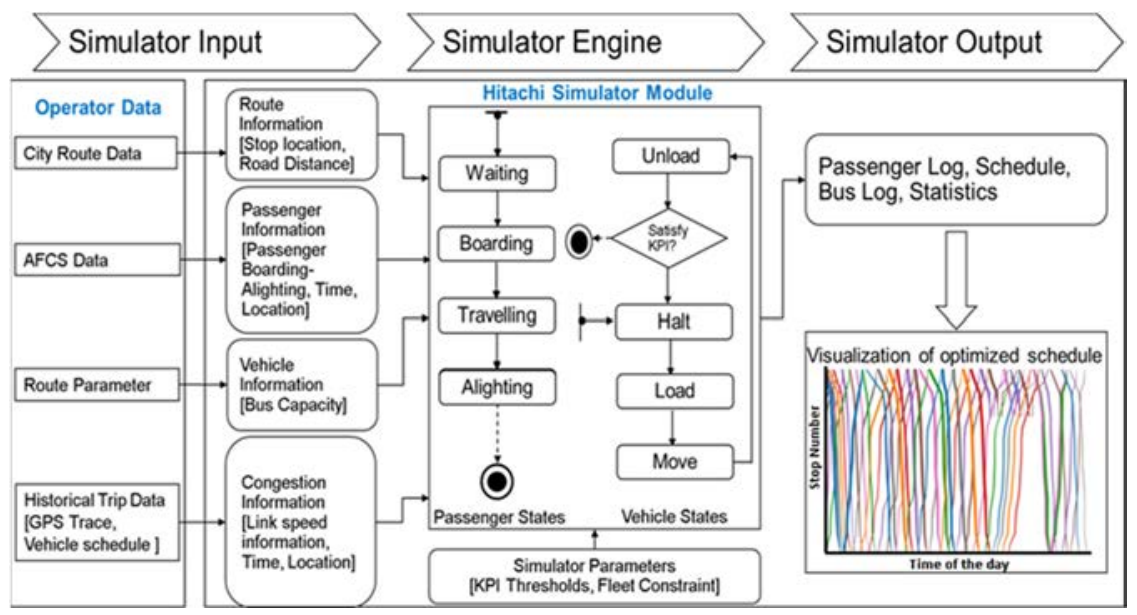

Figure 1: Overview of the bus simulator data processing architecture.

\subsubsection{Deviation from planned operations}

The timetable is generated to satisfy the time-location sensitive demand patterns estimated from the origin destination (OD) demand matrix. In practice, time varying on-road congestion (peak and non-peak hours) is one of the chief causes of the schedule divergence. In Ceder et al. [12], the authors propose to minimize the deviation from the desired passenger load while maintaining even headway to improve utilization. The trip time variability is high without a clear peak, off-peak hour and thus conventional modes of vehicle allocation as per predictable demand is not effective as mentioned in WRI report [13]. At present, operators resort to periodic schedule adjustment based on past observations leading to unsatisfactory 
results. Therefore, development of congestion resilient timetable, that balances the need of passengers and the operator remains a major issue. Two potential solutions are considered:

i. Dynamically alter the bus transport timetable as per the actual trip times in real time

ii. Re-optimize the schedules based on trip times estimated from historical GPS data

Method i can control the desired output, however, needs fundamental change in operations that is not supported by the static schedule. However, this method is suitable to be implemented as the demand responsive public transport especially on Bus Rapid Transport.

The Method ii is suitable for fixed routes with variable trip times. However, it may be noted that it is not only the end-to-end trip time, which is impacted, but also the arrival time at each of the intermediate stops during the trip that gets changed due to the impact of congestion.

In this paper, the Method ii. is considered when historical GPS information is available.

\subsubsection{Insufficient enforcement of regulations}

Service delays, cancellations are also caused due to human factors such as driver behaviour (route violations, disrupting the vehicle to server communication) and passenger behaviours (boarding/alighting at non-designated locations). In these situations, often the trip related data collected is error prone and makes the optimization of schedule inaccurate. Appropriate enforcement of regulations by public transport authorities can make the operations more predictable and hence lead to the efficiency improvement, such as those implemented in developed countries. This issue is surveyed in detail under Operational planning topic of Iliopoulou and Kepaptsoglou [8] and treated as an optimization parameter in Yan et al. [11].

\section{PROPOSED APPROACH}

In this section, the proposed approach for simulation of bus transport schedule is described.

\subsection{Bus transport model}

Fig. 1 shows the overview of the bus schedule simulator with its data processing pipeline. The operator data is available in various formats as there is no common implementation standard. Therefore, either through database API or through individual data files (CSV format), the information is gathered and converted to simulator's custom format. The simulation model creates trips for a regular working day from a start time (say, 06:00 am) to end time (say, 10:00 pm) as per the route data received. Within this time frame, all trips (forward trips as well as return trips) are generated. Bus instances are generated with discrete event simulation and based on the vehicle circulation. The vehicles are placed at the geographical coordinates of the first stop, so in this model the deadhead trip from origin depot to the initial stop of the route is not considered. The states through which the vehicle goes through during the trip are shown in Fig. 1.

The main states are briefly described:

i. Halt: If the bus is at the initial stop of the trip, it is held until the scheduled departure time of the trip. In the current implementation, new candidate trips are generated at periodic micro-intervals and later checked to satisfy the KPI threshold conditions. The trip is accepted and evaluated only if the KPI threshold conditions are satisfied.

ii. Load, Unload: If the position considered is not at the initial or final stop, the bus will load and unload passengers at each stop based on the travel pattern. At the first stop, the bus will only load passengers and at the last stop, the bus will only unload. 
The time it takes to load, unload passengers is currently kept constant, however it can be extended to include observed stopping AVLS times on that route.

iii. Move: After loading and unloading, the bus is moving from one stop to another. The time this takes is drawn from the historical distribution of travel times for that time slot. The distribution is generated by processing the historical GPS traces.

\subsection{Passenger load model}

Passengers are modelled through a boarding-alighting count model at each bus stop on the route for a regularly repeating pre-defined interval. It may be generated from the expected loading levels, or through historical ticket data on that route. Through these models, both historical as well as future growth scenarios can be simulated:

i. Waiting: Passenger waits till the next scheduled bus arrives at that stop. The passenger boarding alighting count is derived from the OD matrix of the travellers computed at the resolution of the simulator's pre-defined interval.

ii. Boarding: When the bus arrives at the stop, the waiting passenger count is reduced due to boarding, which is limited by the capacity and on-board count existing in the arriving bus. Since the simulator allows for the configuration of vehicle model and seating capacity, the on-board passenger count cannot be more than the bus capacity.

iii. Traveling: The passengers travel in the vehicle as per their chosen origin and destination stops. However, in current model each passenger's trip is not traced and only the boarding-alighting behaviour is modelled. The total on board count over each traversed link during the trip is recorded. This provides granular analysis.

iv. Alighting: Once the passenger disembarks from the bus, the model removes the instance from further processing. The on-board count of passengers is appropriately updated to reflect the change. All passengers are forced to alight at the end.

Apart from the above defined simulator inputs, model of passenger and vehicles, the software needs parameters to configure KPI thresholds (shown in Table 3). Simulator output is generated in the JavaScript Object Notation (JSON) format which is a lightweight representation of storing and transporting data. It can be easily parsed to generate statistics for dashboard representation. The output file consists of fields such vehicle number, arrival

Table 3: Simulator configuration parameters.

\begin{tabular}{|l|l|}
\hline Parameter name & Parameter value \\
\hline maxNumOfBus & Integer value indicating the fleet allocated on the route \\
\hline firstTripStart & Time offset in minutes from 00:00 hrs - start time of first trip \\
\hline lastTripDeparture & Time offset in minutes from 00:00 hrs - end time of last trip \\
\hline busCapacity & Maximum number of seated passengers in the vehicle \\
\hline maxOverCapacity & Maximum number of standing passengers in the vehicle \\
\hline haltTime & Minimum time in minutes for which the bus waits \\
\hline minTotalPassengerCount & KPI threshold: Minimum count of passengers \\
\hline minAvgOccupancy & KPI threshold: minimum acceptable average bus occupancy \\
\hline minInterval & $\begin{array}{l}\text { KPI threshold: Minimum interval for insertion of trip at start } \\
\text { point (minutes) }\end{array}$ \\
\hline maxInterval & $\begin{array}{l}\text { KPI threshold: Maximum interval for insertion of trip at start } \\
\text { point (minutes) }\end{array}$ \\
\hline
\end{tabular}


and departure time at each intermediate stop, boarding, alighting passenger counts and occupancies of each link on the trip. These can be easily processed through the visualizer.

\section{DATA MODELS AND ASSUMPTIONS}

In this section, the method of generating model of the link speeds from GPS data as well as the passenger ridership from ticket data is described along with key assumptions.

\subsection{Link speed model}

A route consists of $N$ stops and $N-1$ intermediate links interconnecting the successive stops. From the GPS trace, it is possible to deduce the expected arrival and departure times for each trip. With this information on the travel time variability, a vector of average speeds at that link in the corresponding time period (say, hourly) can be derived. While instantaneous speed of the vehicle is a function of vehicular flow rate through given road dimensions, the representation of vehicular travel time is simplified by proposed approach. In the absence of GPS data, the AVLS information can be used to generate the average vehicular speed between origin and destination. The link speed model for the network under consideration represents the route transport capacity and determines the spatio-temporal variations in trips.

\subsection{Passenger ridership model}

The E-Ticket data is uploaded to the cloud server from the on-board device. This data consists of the origin, destination stop of the passenger, time of ticket issue and number of passengers. If the count of boarding-alighting passenger at every stop at every period is grouped from above information, a basic model of the ridership is obtained. This model can also be generated through the Automatic Passenger Count (APC) systems. It can also be enhanced with additional information for every ticket that indicates the travelled route length. From the Fig. 2, the spatial and temporal variations of the boarding, alighting passenger count across time and as per the stops. These patterns change for each route based on the relative positioning of trip generations and attractions (for example, residential areas and workplaces).

The presence of substantial peaks in certain space-time zones show localized demand that are best served by short turn routes. Fig. 3 shows the same information with heatmap representation over the matrix. The sudden increase in ridership in a segment of the route

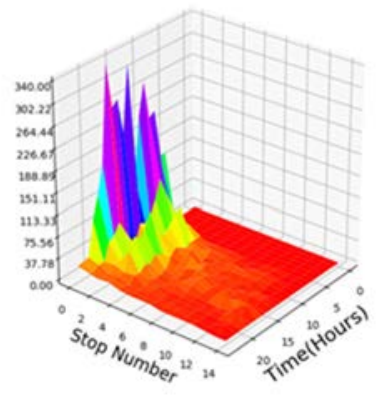

(a)

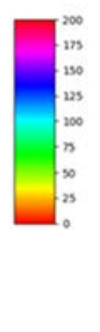

Figure 2: Spatio-temporal passenger ridership model. (a) Boarding; (b) Alighting pattern.
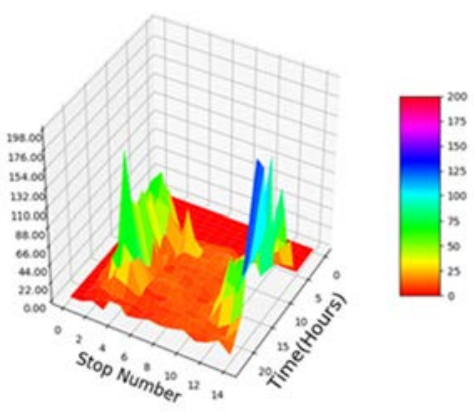

(b) 


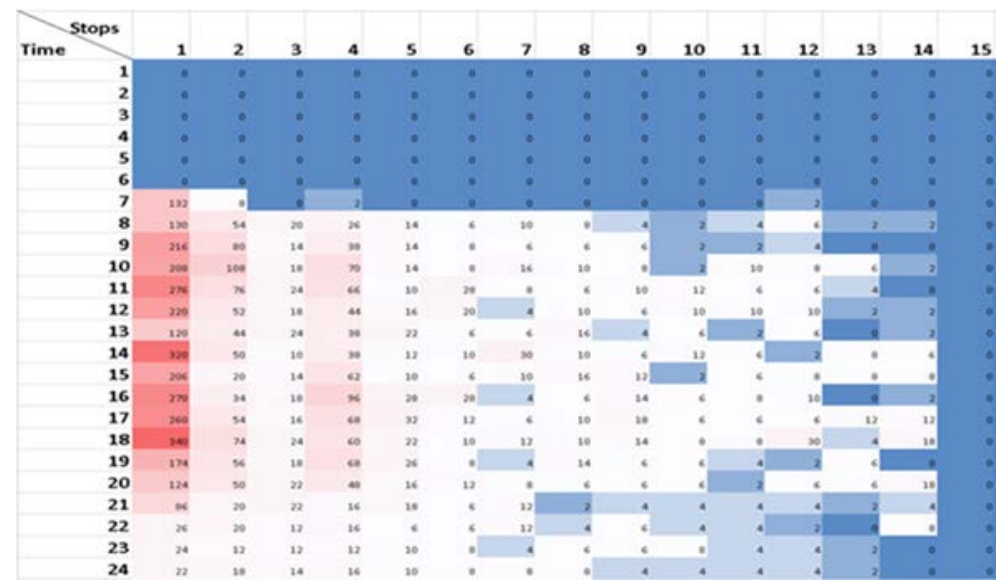

(a)

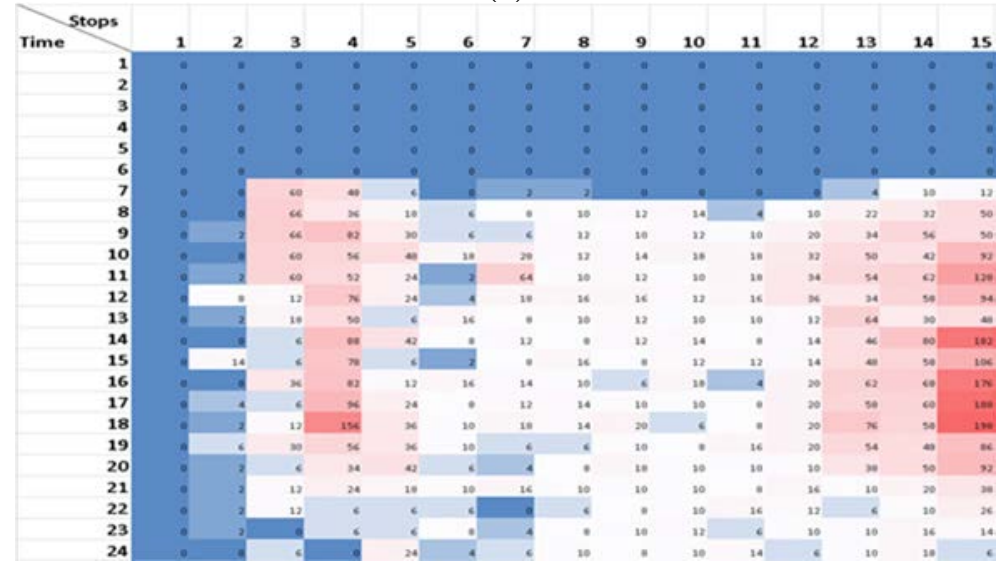

(b)

Figure 3: Passenger ridership heat map. (a) Boarding pattern; (b) Alighting pattern.

indicated by boarding and alighting locations in the middle hours of the day indicate the need for short turn routes to balance the overall load factor and fleet requirement.

\section{RESULTS AND DISCUSSION}

Synthetic ridership of a developing city based on historical pattern, operator's schedule as in WRI report [14] is generated. The existing schedule of the operator is fixed frequency that results in a mismatch between the passenger demand and bus availability leading to uneven load distribution. From Figs 2 and 3, it is evident that during peak hours there is sudden increase in the passengers riding between Stop 1 and Stop 4. Two strategies to generate schedules are presented. (i) Full route trips and (ii) Mixture of full and short trips.

\subsection{Full route trips schedule}

Fig. 4 shows the result of the simulated, optimized schedule with all end-to-end trip schedules. These trips consider the presence of a bus dispatch depot at both ends of the route. 
However, when the load levels between each pairs of OD stations are considered, it is seen that high passenger boarding demand is limited to certain stations and not uniformly distributed. The trips that satisfy the KPI (Avg. load factor $>=0.5$ ) are selected and plotted. In total, there are 91 trips (48 forward trips, 43 reverse trips) with avg. load factor (0.66) and 8 vehicles are utilized. In the Fig. 4, each unique vehicle is depicted as separate colour and width of each line is proportional to the load factor of the trip. The details of hourly dispatch frequency and average load factor are plotted in Fig. 5. It can be clearly seen that each accepted trip schedule is experiencing an acceptable load factor $(0.5$ to 0.8$)$.

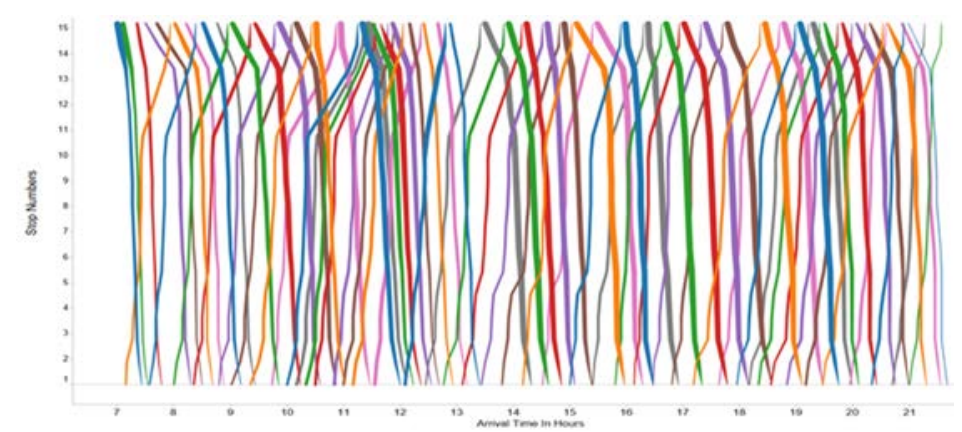

Figure 4: Time-space chart of the optimized schedule with full trip operations.

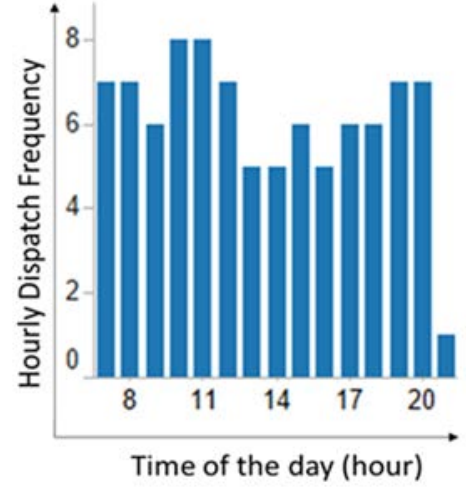

(a)

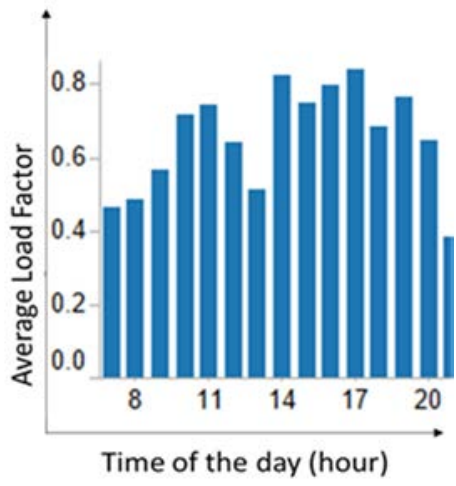

(b)

Figure 5: Key characteristics of: (a) Hourly dispatch frequency; and (b) Average load factor.

Advantages of proposed end-to-end trip schedule:

i. This strategy is easier to be implemented in practice by operator and reduces the risk of dead-head trips where the passengers are not boarded.

ii. End-to-end trip schedules are easily interpretable by the operator and differs from existing trip schedule only in the operating strategy (skipped stops, departure time).

Shortcomings of proposed end-to-end trip schedule:

i. Scheduling new end-to-end bidirectional trips when the load is limited to certain route segments is considered inefficient and leads to increase in the operational cost. 
ii. Uneven load dependent dispatch frequencies are harder to understand for the passengers in the absence of real time tracking and passenger information systems.

\subsection{Mixture of full and short trips schedule}

Fig. 6 shows the result of the simulated optimized schedule with both end-to-end trip schedules as well as the short route trip schedule. In this case, for the same ridership, the number of end-to-end trips reduces to 88 , with insertion of 14 short trips. The average loading factor also marginally reduces to 0.62 that indicates lower in bus crowding. The details of hourly dispatch frequency and average load factor are plotted in the Fig. 7. It can be clearly seen that each accepted trip schedule is experiencing an acceptable load factor (0.5 to 0.8$)$.

Advantages of the proposed mixed trip schedule include the improvement of fleet utilization for high-demand segment, achieved by insertion of short turn trips in-line with the full route trips, which improves vehicle reuse.

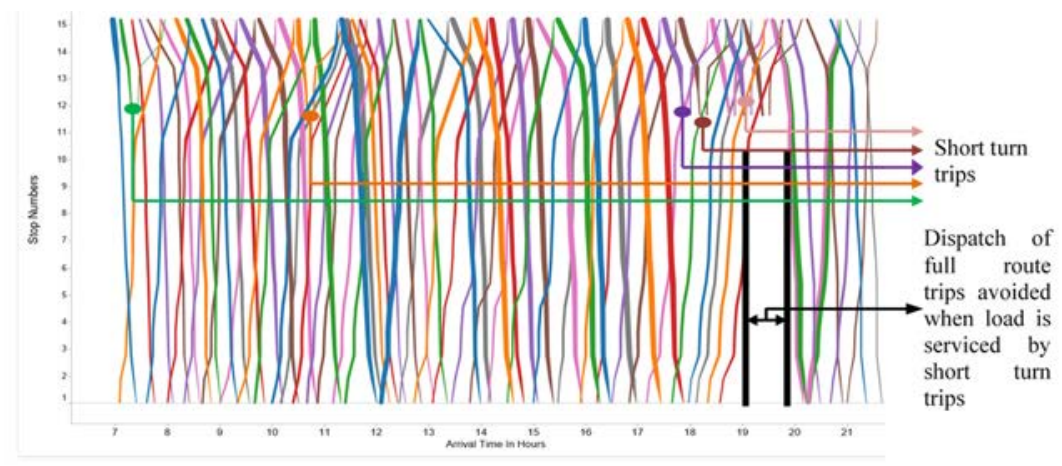

Figure 6: Time-space chart of the optimized schedule with full and short trip operations.

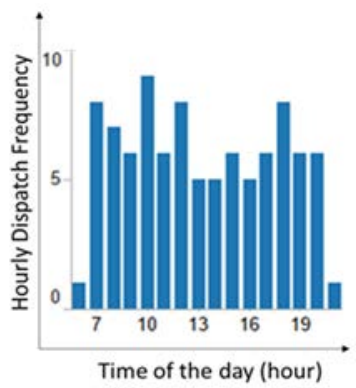

(a)

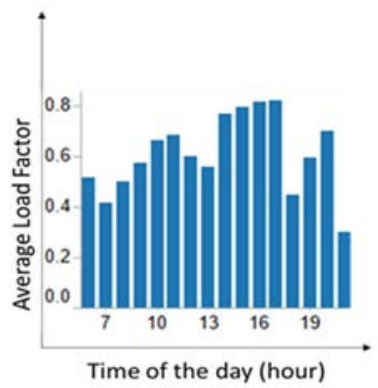

(b)

Figure 7: Key characteristics of (a) hourly dispatch frequency and (b) average load factor.

Shortcomings of the proposed mixed trip schedule include challenge to optimize placement of depots. Since the placement of depots in most cases are closer to the end points of the route, it is not possible to serve short trips in the interior segments of the route without return of vehicles to the depot. 


\subsection{Discussion of results}

The basic advantage of simulation driven schedule optimization is the ability to perform scenario-based analysis (What-If analysis). Table 4 shows an example of comparison between two operational strategies with the same number of vehicles in the fleet. It can be observed that for the load scenario considered, introduction of short trips can reduce the average load factor.

Table 4: Summary of generated schedules.

\begin{tabular}{|l|c|l|c|}
\hline Schedule type & Fleet count & Number of trips simulated & Avg. load factor \\
\hline Full route & 8 & Forward -48, reverse -43 & 0.66 \\
\hline Mixture of full and short & 8 & $\begin{array}{l}\text { Forward }-47, \text { reverse }-45 \\
\text { including 14 short trips }\end{array}$ & 0.62 \\
\hline
\end{tabular}

The short trips are approximately $46 \%$ shorter than the full trips and hence save substantial operational cost through improvement of vehicle utilization.

Currently, this simulator is used in the operational context of the public transport and needs repeatable results, for which the following assumptions based on Dalle [15] are made:

i. Usage of platform-independent solution: Computing platform and programming language can influence the execution sequence and therefore use of platform independent programming language is important for reproducibility. In the current work, JAVA is the programming language which is platform independent. The next level of independence to be considered in future is the adoption of a simulation framework (for example, Petri Nets).

ii. Ensure the availability of the computing solution: Distribution of simulation software to users using pre-configured virtual machine (appliance) is a preferred mode considering the complexity of configuring simulation parameters, inputs such as route details and operator data formats.

However, the current simulator has the following limitations:

i. User defined constraint optimization: Some operators specify special constraints related to usage of crew, vehicles and the flexibility of resource sharing. While it is difficult to design a general simulator including all such cases, the transport operator expects simulation results that adhere to these actual conditions. Hence simulator needs to be extensible.

ii. Primary survey data-based optimization: While AFCS information provides the historical ridership information, operators rely on primary data surveys of potential passengers. Our current simulator does not assume availability of such data source for schedule optimization.

\section{CONCLUSIONS}

In this paper, new schedule simulator for target bus routes is proposed to improve the trip time reliability, bus ridership load levels and operational headways. From the results it can be concluded that, this method is effective in producing schedules that can be validated by the operators experience as well as reduces the effort in optimizing the timetable for future scenario. The bus schedules once published are active over long periods (weeks or months) and the passenger load models derived from ticket data needs further validation incorporating long term effects that capture the seasonal variations and impact of special events (such as 
sports). Further, the impact of disruptions that lead to schedule change or cancellations need to be incorporated. In this research, our target has been those routes which directly connect a pair of source and destination stops. In future, additional operational strategies such as multiroute schedule, circular and special vehicles (electric bus etc.) would be incorporated.

\section{REFERENCES}

[1] Pojani, D. \& Stead, D., Sustainable urban transport in the developing world: Beyond megacities. Sustainability, 7, pp. 7784-7805, 2015.

[2] De La Mota, I.F. \& Huerta-Barrientos, A., Simulation-optimization of the Mexico City public transportation network: A complex network analysis framework. Applied Simulation and Optimization, 2, pp. 43-79, 2017.

[3] Bastian, M., Heymann, S. \& Jacomy, M., Gephi: An open source software for exploring and manipulating networks. Presented at International AAAI Conference on Weblogs and Social Media, 2009.

[4] Hawas, Y.E., Simulation-based regression models to estimate bus routes and network travel times. Journal of Public Transportation, 16(4), 2013.

[5] Ibarra-Rojas, O.J., Delgado, F., Giesen, R. \& Muñoz, J.C., Planning, operation, and control of bus transport systems: A literature review. Transportation Research Part B, 77, pp. 38-75, 2015.

[6] Song, M., Mogeng, Y. \& Xiqun, C., A simulation-based approach for sustainable transportation systems evaluation and optimization: Theory, systematic framework and applications. Procedia - Social and Behavioral Sciences, 96, pp. 2274-2286, 2013.

[7] Hajinasab, B., Davidsson, P., Persson, J.A. \& Holmgren J., Towards an agent-based model of passenger transportation. Multi-Agent Based Simulation XVI. MABS 2015. Lecture Notes in Computer Science, 9568. Springer, Cham, 2016.

[8] Iliopoulou, C. \& Kepaptsoglou, K., Combining ITS and optimization in public transportation planning: state of the art and future research paths. European Transport Research Review, 11, 2019.

[9] Gkiotsalitis, K. \& Cats, O., Reliable frequency determination: Incorporating information on service uncertainty when setting dispatching headways. Transportation Research Part C: Emerging Technologies, 88, pp. 187-207, 2018.

[10] Wang, Y., Zhang, D., Hu, L., Yang, Y. \& Lee, L.H., A data-driven and optimal bus scheduling model with time-dependent traffic and demand. IEEE Transactions on Intelligent Transportation Systems, 18(9), pp. 2443-2452, 2017.

[11] Yan, Y., Meng, Q., Wang, S. \& Guo, X., Robust optimization model of schedule design for a fixed bus route. Transportation Research Part C: Emerging Technologies, 25, pp. 113-121, 2012.

[12] Ceder, A., Hassold, S. \& Dano, B., Approaching even-load and even-headway transit timetables using different bus sizes. Public Transport, 5(3), pp. 193-217, 2013.

[13] WRI, Bus Karo 2.0 - Case Studies from India, Online. https://wricitieshub.org/onlinepublications/11-recent-trends-urban-bus-transport-india. Accessed on: 3 Jun. 2019.

[14] EMBARQ, Data collection and analysis for public transport. Report for the World Resources Institute (WRI). https://wricitieshub.org/sites/default/files/Data\%20 collection $\% 20$ and $\% 20$ analysis $\% 20$ for $\% 20$ public\%20transport.pdf. Accessed on: 3 Jun. 2019.

[15] Dalle, O., On reproducibility and traceability of simulations. Proceedings of the 2012 Winter Simulation Conference (WSC), pp. 1-12, 2012. 